\title{
Adipose-derived resistin and gut-derived resistin-like molecule- $\beta$ selectively impair insulin action on glucose production
}

\author{
Michael W. Rajala, ${ }^{1}$ Silvana Obici, ${ }^{2,3}$ Philipp E. Scherer, ${ }^{1,3}$ and Luciano Rossetti ${ }^{2,3,4}$ \\ ${ }^{1}$ Department of Cell Biology, \\ ${ }^{2}$ Department of Medicine, \\ ${ }^{3}$ Diabetes Research and Training Center, and \\ ${ }^{4}$ Department of Molecular Pharmacology, Albert Einstein College of Medicine, Bronx, New York, USA
}

The adipose-derived hormone resistin is postulated to link obesity to insulin resistance and diabetes. Here, the infusion of either resistin or the resistin-like molecule- $\beta(\operatorname{RELM} \beta)$ rapidly induced severe hepatic but not peripheral insulin resistance. In the presence of physiologic hyperinsulinemia, the infusion of purified recombinant resistin, increasing circulating resistin levels by approximately twofold to 15 -fold, inhibited glucose metabolism such that lower rates of glucose infusion were required to maintain the plasma glucose concentration at basal levels. The effects of resistin and RELM $\beta$ on in vivo insulin action were completely accounted for by a marked increase in the rate of glucose production. These results support the notion that a novel family of fat- and gut-derived circulating proteins modulates hepatic insulin action.

J. Clin. Invest. 111:225-230 (2003). doi:10.1172/JCI200316521.

\section{Introduction}

Resistin belongs to a new gene family of small cysteine-rich secreted proteins (1-4). The other two members of the family, resistin-like molecule- $\alpha$ RELM $\alpha$ (also known as FIZZ1) and RELM $\beta$ (also known as FIZZ2), are about $60 \%$ similar to resistin and are expressed in the stromal components of lung $(2,3)$ and adipose tissue (4) and in epithelial cells of the intestine $(2,3)$, respectively. This family of circulating proteins is likely to play a role in the complex interorgan communication network, which appears to modulate intermediate metabolism (5-10) and energy balance $(5,6,9)$.

Adiposity is coupled to insulin action via largely unknown mechanisms $(11,12)$. Furthermore, the systemic actions of insulin-sensitizing drugs that target transcriptional regulation in adipose cells suggest a causal role of adipocyte function in the regulation of insulin sensitivity $(1,7,13)$. Circulating proteins secreted by adipose tissue could partly account for this link via modulation of insulin action in distant organs ${ }^{1,4-10}$. In this regard, the potential role of resistin (also known

Received for publication July 26, 2002, and accepted in revised form October 22, 2002.

Address correspondence to: Luciano Rossetti, Department of Molecular Pharmacology and Diabetes Research and Training Center, Albert Einstein College of Medicine, 1300 Morris Park Avenue, Bronx, New York 10461, USA. Phone: (718) 430-4118; Fax: (718) 430-8557; E-mail: rossetti@aecom.yu.edu.

Conflict of interest: P.E. Scherer has received an unrestricted grant from Pfizer (Groton, Connecticut, USA).

Nonstandard abbreviations used: resistin-like molecule- $\beta$ (RELM $\beta$ ); uridine diphosphoglucose (UDP-glucose); phosphoenolpyruvate (PEP). as ADSF and FIZZ3) in the regulation of glucose metabolism is based on its discovery in plasma, its exclusive expression in adipose tissue, and the initial characterization of its biological functions (1).

To determine whether acute increases in circulating levels of resistin worsen glucose tolerance (1), either by decreasing glucose uptake, increasing glucose production, or both, we combined the pancreatic insulin clamp technique $(14,15)$ with infusions of resistin, RELM $\beta$, or vehicle control in conscious rats. Recombinant RELM $\beta$ was tested to explore whether this gutderived member of the resistin family shares resistin's metabolic properties.

\section{Methods}

Animals. Adult male Sprague Dawley rats were anesthetized and catheterized through the right internal jugular vein and the left carotid artery as previously described (14-17).

Recombinant resistin and RELM $\beta$. The entire open reading frames of resistin and RELM $\beta$ were cloned into pFM1, which contains an internal ribosome entry site, followed by the open reading frame of green fluorescent protein as previously described (7). Stably transfected HEK293 T cells were sorted by FACS (Becton, Dickinson and Co., Franklin Lakes, New Jersey, USA) for high levels of green fluorescent protein expression, and therefore high resistin or RELM $\beta$ expression. Five sorts of enrichment established a line of cells capable of producing milligram quantities of recombinant protein per liter of media. Serum-free media was used to collect the secreted protein from confluent cells for 2 days. The media was then harvested and spun down to 
remove cells, and the $\mathrm{pH}$ was adjusted to 6.0 with 20 $\mathrm{mM}$ Bis-Tris, $\mathrm{pH}$ 6.0. The media was then filtered with a $0.22-\mu \mathrm{m}$ filter and loaded directly onto an Econo-Pac $\mathrm{S}$ ion exchange column (Bio-Rad Laboratories Inc., Hercules, California, USA). The protein was then eluted with a step salt gradient from $200 \mathrm{mM}$ to $300 \mathrm{mM}$ $\mathrm{NaCl}$, followed by a continuous gradient of $300 \mathrm{mM}$ to $1 \mathrm{M} \mathrm{NaCl}$. Two major peaks were apparent, with resistin/RELM $\beta$ eluting in the second peak between about 350 and $500 \mathrm{mM} \mathrm{NaCl}$. This eluate was then concentrated by centrifugation in a Centricon YM-3 filter (Millipore Corp., Bedford, Massachusetts, USA) and loaded onto a Superdex 200 size filtration column (Amersham Pharmacia Biotech, Piscataway, New Jersey, USA). The major peak contained at least $99 \%$ pure recombinant protein.

Measurement of resistin protein levels in plasma. Plasma mouse resistin was measured by semiquantitative Western blotting as described (4). This analysis was possible since resistin protein abundance in plasma samples was within the linear portion of the standard curve during the infusion (Figure 1b). Five microliters of serum was loaded per lane. Multiple exposures were analyzed by spot densitometry to insure linearity of the standard curve.

Detection of endogenous RELM $\beta$ protein in plasma. Plasma RELM $\beta$ was immunoprecipitated followed by Western blotting (Figure 1c). Either $0.5 \mathrm{ml}$ or $1 \mathrm{ml}$ of serum was used.

Measurements of in vivo glucose kinetics and pancreatic insulin clamp procedures. Food was removed 5 hours before the beginning of in vivo studies. The infusion studies lasted a total of 300 minutes (Figure 1a).

\footnotetext{
Figure 1

(a) Schematic representation of the pancreatic and insulin clamp procedure. During the first 2 hours, the rate of insulin infusion was adjusted periodically in order to maintain the plasma glucose concentration at basal levels (insulin as needed). During the last $30 \mathrm{~min}$ utes of this 2-hour period, the rate of insulin infusion was stable in all rats and these individualized rates were continued throughout the study. At the completion of the pancreatic clamp (at $t=120 \mathrm{~min}$ utes), an additional infusion of insulin $(3 \mathrm{mU} / \mathrm{kg} / \mathrm{min})$ was administered to similarly raise the plasma insulin levels in all groups, and a variable infusion of a $25 \%$ glucose solution was started and periodically adjusted (glucose as needed) to maintain the plasma glucose concentration at approximately $7 \mathrm{mM}$ for the rest of the study. (b) Time course of plasma resistin during pancreatic and insulin clamps. Quantitation of Western blots was achieved by comparison to a standard curve of increasing amounts of recombinant mouse resistin (left panels). Bottom panels show representative Western blot analysis of plasma from rats infused with mouse resistin $(\mathrm{mU} / \mathrm{kg} / \mathrm{min})$ at the rate of $5 \mu \mathrm{g} / \mathrm{h}$ (low) and $25 \mu \mathrm{g} / \mathrm{h}$ (high). A single band was recognized at about $10 \mathrm{kDa}$. Comparison with standards allowed us to estimate the serum concentration of mouse resistin during the infusion studies. Basal levels of plasma resistin in C57BL/ 6 mice averaged $81 \pm 23 \mathrm{ng} / \mathrm{ml}$ using this semiquantitative Western analysis. (c) Detection of plasma RELM $\beta$ in rat plasma. One-half $\mathrm{ml}$ or $1 \mathrm{ml}$ of serum was used in immunoprecipitation (IP) experiments followed by Western blots (left). The antibody detected recombinant (Rec.) RELM $\beta$ but not recombinant resistin (right).
}

Briefly, at $t=0$, a primed, continuous intra-arterial infusion of resistin, RELM $\beta$, or vehicle was initiated and maintained for the remainder of the study. The total dose of resistin was $30 \mu \mathrm{g} / \mathrm{rat}$ and $150 \mu \mathrm{g} / \mathrm{rat}$ during the low-dose and high-dose studies, respectively. The total dose of RELM $\beta$ was $120 \mu \mathrm{g} / \mathrm{rat}$. Primed, continuous infusions of somatostatin ( 3 $\mu \mathrm{g} / \mathrm{kg} / \mathrm{min}$ ) and of HPLC-purified [ ${ }^{3} \mathrm{H}-3$ ] glucose (40 $\mu \mathrm{Ci}$ bolus, $0.4 \mu \mathrm{Ci} / \mathrm{min}$; NEN Life Science Products Inc., Boston, Massachusetts, USA) were also started at $t=0$ and continued for the duration of the study (14-17). During the first 2 hours of the clamp, the rate of insulin infusion was adjusted periodically in order to maintain plasma glucose concentration at basal levels. During the last 30 minutes of this 2-hour period, the rates of insulin infusion were stable in all rats, and these individualized rates were then continued for the rest of the study. At the completion of the modified pancreatic clamp period (at $t=120$ minutes), an additional infusion of regular insulin (3 $\mathrm{mU} / \mathrm{kg} / \mathrm{min}$ ) was administered in order to similarly raise the plasma insulin levels in all groups. A variable infusion of a $25 \%$ glucose solution was then started and periodically adjusted to maintain the plasma glucose concentration at approximately $7 \mathrm{mM}$ for the rest of the study. Ten minutes before the end of the in vivo studies, [U-14 C]lactate $(20 \mu \mathrm{Ci}$ bolus, 1.0 $\mu \mathrm{Ci} / \mathrm{min}$; NEN Life Science Products Inc.) was administered in order to determine the contribution of gluconeogenesis to the hepatic glucose-6-phosphate pool. Samples for determination of $\left[{ }^{3} \mathrm{H}-3\right]$ glucose specific activity were obtained at 10-minute intervals throughout the infusions.

a
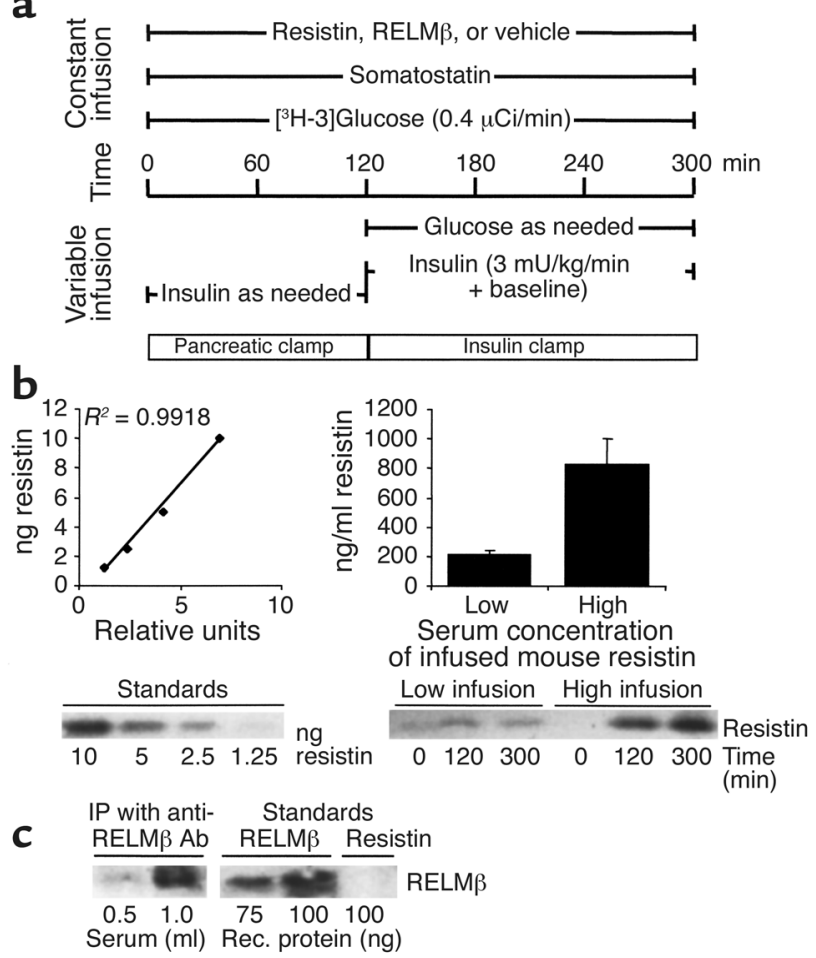


\section{Table 1}

General characteristics of rats receiving resistin, $\operatorname{RELM} \beta$, or vehicle before and during pancreatic insulin clamp studies

Vehicle Resistin (low) Resistin (high) RELM $\beta$

Basal

$n$

Body wt $(\mathrm{g})$

Glucose $(\mathrm{mM})$

Insulin $(\mu \mathrm{U} / \mathrm{ml})$

Pancreatic clamp

Glucose (mM)

Insulin $(\mu \mathrm{U} / \mathrm{ml})$

Insulin clamp

Glucose $(\mathrm{mM})$

Insulin $(\mu \mathrm{U} / \mathrm{ml})$

$\begin{array}{cc}5 & 7 \\ 327 \pm 6 & 317 \pm 8 \\ 8.5 \pm 0.3 & 8.3 \pm 0.3 \\ 21 \pm 4 & 23 \pm 3\end{array}$

$8.2 \pm 0.4$

$19 \pm 4$

$9.6 \pm 0.6^{\mathrm{A}}$

$31 \pm 4^{\mathrm{A}}$

$7.1 \pm 0.2$

$7.2 \pm 0.3$

$97 \pm 7$

$106 \pm 8$

$\begin{array}{cc}8 & 5 \\ 326 \pm 9 & 315 \pm 11 \\ 8.4 \pm 0.4 & 8.2 \pm 0.3 \\ 23 \pm 3 & 24 \pm 5\end{array}$

$8.5 \pm 0.6$

$37 \pm 5^{\mathrm{A}}$

$8.7 \pm 0.8$

$29 \pm 6^{A}$

$6.9 \pm 0.2 \quad 7.0 \pm 0.3$
$105 \pm 10 \quad 99 \pm 7$

Rats were fasted for 5 hours prior to plasma sampling. Biochemical parameter values represent mean \pm SEM. ${ }^{A} P<0.01$ vs. vehicle.

The specific activities of hepatic ${ }^{14} \mathrm{C}$-labeled phosphoenolpyruvate (PEP), ${ }^{3} \mathrm{H}$-labeled uridine diphosphoglucose (UDP-glucose), and ${ }^{14} \mathrm{C}$-labeled UDP-glucose were measured by HPLC and the rates of PEP gluconeogenesis were calculated. The percentage of the hepatic glucose-6-phosphate pool directly derived from plasma glucose (direct pathway) was calculated as the ratio of liver $\left[{ }^{3} \mathrm{H}\right] \mathrm{UDP}$-glucose and plasma $\left[{ }^{3} \mathrm{H}-3\right]$ glucose specific activities.

Gluconeogenesis was estimated from the specific activities of hepatic ${ }^{14} \mathrm{C}$-labeled UDP-glucose (assumed to reflect the specific activity of hepatic glucose-6-phosphate) and hepatic PEP following the infusion of $\left[\mathrm{U}-{ }^{14} \mathrm{C}\right]$ lactate and $\left[{ }^{3} \mathrm{H}-3\right]$ glucose using the following formula (17): gluconeogenesis $=\mathrm{TGO} \times$ $\left[{ }^{14} \mathrm{C}\right]$ UDP-glucose SA $/\left[{ }^{14} \mathrm{C}\right]$ PEP SA $\times 2$, where $\mathrm{TGO}=$ the sum of glucose production and glucose cycling and $\mathrm{SA}=$ specific activity.

Statistics. All values are presented as mean \pm SEM. Differences were considered statistically significant at $P<0.05$. Comparisons among groups were made using ANOVA followed by an unpaired, nonparametric Student $t$ test. The study protocol was reviewed and approved by the Institutional Animal Care and Use Committee of the Albert Einstein College of Medicine.

\section{Results}

Conscious rats were given an initial intra-arterial bolus of either resistin, RELM $\beta$, or vehicle, followed by an intra-arterial infusion of the same material at a constant rate (Figure 1a). Resistin was infused at either $5 \mu \mathrm{g} / \mathrm{h}$ (low) or $25 \mu \mathrm{g} / \mathrm{h}$ (high), which promptly increased its serum concentration approximately two- to fivefold or ten- to 15 -fold, respectively (Figure $1 \mathrm{~b})$. RELM $\beta$ or vehicle was infused at $20 \mu \mathrm{g} / \mathrm{h}$. Prior to the start of the infusion protocols, there were no differences in mean body weight, plasma insulin, or glucose concentration among the four groups of rats (Table 1).

We used a modification of the pancreatic clamp technique designed to accurately estimate the impact of recombinant resistin and RELM $\beta$ on glucose fluxes in the presence of either low or physiologically high insulin concentrations (Figure 1a, Table 1). To prevent the endogenous secretion of glucoregulatory hormones such as insulin and glucagon, we administered somatostatin, which effectively blunts secretion of these hormones. Thus, without endogenous insulin, a known infusion of insulin could be administered at a constant rate, periodically adjusted to maintain plasma glucose concentrations at a physiologic level $(\sim 8.5 \mathrm{mM})$. This technique effectively minimized the confounding effects of hypoglycemia and its attendant counterregulatory responses on metabolic parameters. In fact, the plasma glucagon $(53 \pm 7$, $56 \pm 5,53 \pm 2$, and $48 \pm 2 \mathrm{ng} / \mathrm{ml}$ ) and corticosterone $(178 \pm 13,196 \pm 36,156 \pm 40$, and $142 \pm 29 \mathrm{ng} / \mathrm{ml})$ concentrations during the insulin clamp studies were similar in rats receiving vehicle, low- and high-dose resistin, and RELM $\beta$, respectively. Additionally, the use of radioactive glucose tracers $(16,17)$ allowed us to measure glucose fluxes in vivo.

The effects of resistin, RELM $\beta$, and vehicle were first compared in the presence of similar steady-state normoglycemia and individualized plasma insulin concentrations (Table 1) in conscious rats. Under these conditions, the levels of circulating insulin necessary to
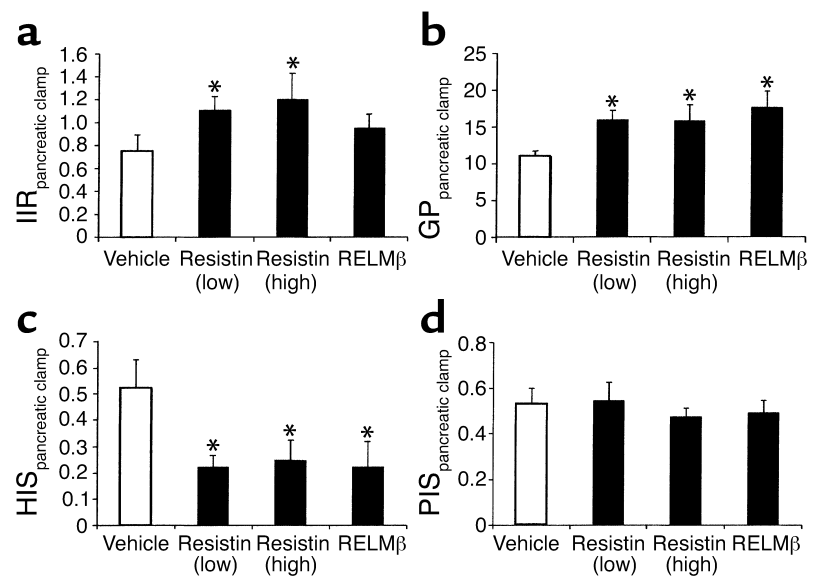

\section{Figure 2}

Effect of resistin and RELM $\beta$ during pancreatic clamp studies. The measurements were obtained while plasma glucose concentration was maintained at approximately $8.5 \mathrm{mM}$ under steady-state conditions. (a) Rates of insulin infusion (IIR; $\mathrm{mU} / \mathrm{kg} / \mathrm{min}$ ) required to maintain the plasma glucose concentrations at basal levels. (b) Effect of resistin and RELM $\beta$ on the rate of glucose production (GP; $\mathrm{mg} / \mathrm{kg} / \mathrm{min}$ ). (c) Effect of resistin and RELM $\beta$ on hepatic insulin sensitivity (HIS). To take into account the differences in circulating plasma insulin levels during the pancreatic clamp studies, an index of HIS was calculated as $\mathrm{GP}^{-1} /$ insulin $(\mu \mathrm{U} / \mathrm{ml}) \times 100$. (d) Effect of resistin and RELM $\beta$ on peripheral insulin sensitivity (PIS). To take into account the differences in circulating plasma insulin levels during the pancreatic clamp studies, an index of peripheral insulin sensitivity was calculated as $\mathrm{Rd}(\mathrm{mg} / \mathrm{kg} / \mathrm{min}) /$ insulin $(\mu \mathrm{U} / \mathrm{ml})$. Rd, rate of glucose disappearance. ${ }^{*} P<0.05$ vs. vehicle. 


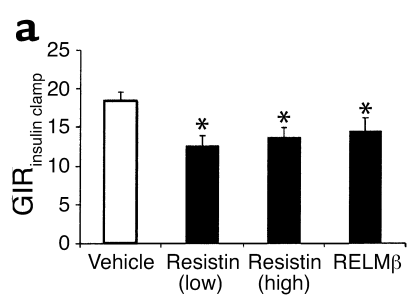

$\mathbf{b}_{30}$

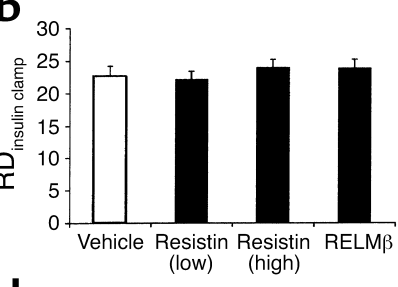

C

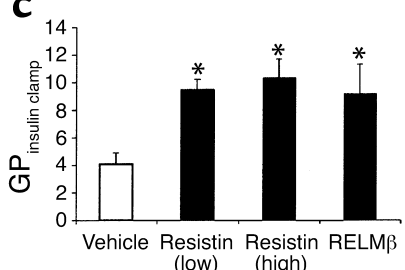

(low) (high)

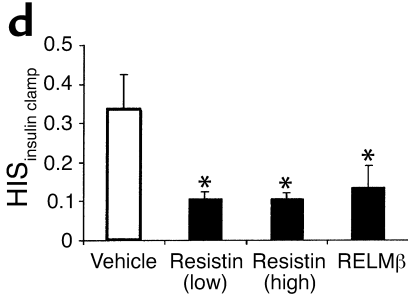

\section{Figure 3}

Effect of resistin and RELM $\beta$ on glucose disposal and production during insulin clamp studies. The measurements were obtained while plasma glucose concentration was maintained at approximately 7 $\mathrm{mM}$ under steady-state conditions. (a) Effect of resistin and RELM $\beta$ on the rate of glucose infusion (GIR; $\mathrm{mg} / \mathrm{kg} / \mathrm{min}$ ). (b) Effect of resistin and RELM $\beta$ on the rate of glucose disappearance (Rd; $\mathrm{mg} / \mathrm{kg} / \mathrm{min}$ ). (c) Effect of resistin and RELM $\beta$ on the rate of glucose production (GP; $\mathrm{mg} / \mathrm{kg} / \mathrm{min}$ ). (d) Effect of resistin and RELM $\beta$ on hepatic insulin sensitivity (HIS; $\mu \mathrm{U} / \mathrm{ml}$ ). To take into account differences between animals in circulating plasma insulin levels during the insulin clamp studies, the same index of hepatic insulin sensitivity described in the Figure $2 c$ legend was used. ${ }^{*} P<0.05$ vs. vehicle. maintain the plasma glucose concentrations at basal levels provide a measure of whole-body insulin effectiveness (Table 1). During the intravenous infusion of resistin and RELM $\beta$, insulin had to be infused at a higher rate than during vehicle infusions (Figure 2a). Furthermore, the rate of glucose production was markedly elevated in both resistin- and RELM $\beta$-infused rats compared with vehicle-infused rats (Figure $2 b$ ). Of note, this occurred despite higher circulating insulin levels (Table 1). Therefore, the presence of increased glucose production in the face of elevated insulin concentrations provides a first demonstration of the potent inhibitory effects of these hormones on hepatic insulin sensitivity (Figure 2c). By contrast, neither resistin nor RELM $\beta$ significantly altered the effect of insulin on peripheral glucose uptake (Figure $2 \mathrm{~d}$ ).

We next examined the effect of increased circulating insulin concentrations on the rates of glucose infusion and tissue glucose uptake (Figure 3, a and b). During this period, insulin levels were elevated in all groups by the same amount (initial infusion rate $+3 \mathrm{mU} / \mathrm{kg} / \mathrm{min})$. Importantly, all measurements were performed during the final 2 hours of the 3-hour hyperinsulinemic clamp study (14-17), a time after steady-state conditions for plasma glucose and insulin concentrations, glucose specific activity, and rates of glucose infusion were achieved. The rates of exogenous glucose infusion (GIR in Figure 3a) required to maintain the target plasma glucose concentration during physiologically high insulin were decreased by $32 \%, 26 \%$, and $25 \%$, respectively, during the infusions of low-dose resistin, high-dose resistin, and RELM $\beta$ compared with vehicle-infused rats. However, the infusion of recombinant resistin (low and high dose) or RELM $\beta$ did not significantly alter the rates of glucose uptake (respectively, $22.1 \pm 1.3$, $23.9 \pm 1.2$, and $23.9 \pm 1.4 \mathrm{mg} / \mathrm{kg} / \mathrm{min}$ ) compared with vehicle $(23.7 \pm 1.6 \mathrm{mg} / \mathrm{kg} / \mathrm{min})$ (Figure 3b). By contrast, in the presence of similar plasma insulin concentrations $(\sim 100$

Table 2 $\mu \mathrm{U} / \mathrm{ml})$, glucose production was higher during the infusion of resistin and RELM $\beta$ than during vehicle infusion (Figure 3c). In fact, this marked impairment in the inhibitory action of insulin on glucose production (Figure 3d) completely accounted for the decreased rate of glucose infusion during the clamp studies. These results indicate that short-term intraarterial infusion of resistin stimulates glucose production in the presence of either basal replacement insulin concentrations or moderately elevated hyperinsulinemia. Thus, regulation of hepatic glucose production is the main mechanism by which resistin acutely regulates glucose tolerance. Of interest, the infusion of recombinant RELM $\beta$ generated metabolic effects qualitatively similar to those of resistin. Glucose production represents the net contribution of glucosyl units derived from gluconeogenesis and glycogenolysis. However, a portion of glucose entering

Effect of resistin and RELM $\beta$ on the direct and "indirect" pathways of hepatic UDP-glucose formation

\begin{tabular}{|c|c|c|c|c|}
\hline & Vehicle & Resistin (low) & Resistin (high) & RELM $\beta$ \\
\hline$\left[{ }^{3} \mathrm{H}\right]$ UDP-glucose & $4.2 \pm 0.7$ & $5.1 \pm 0.5$ & $6.5 \pm 0.6$ & $4.1 \pm 0.5$ \\
\hline \multicolumn{5}{|c|}{ Liver SA (dpm/nmol) } \\
\hline$\left[{ }^{3} \mathrm{H}-3\right]$ Glucose & $22.5 \pm 2.0$ & $21.9 \pm 1.4$ & $23.5 \pm 1.5$ & $20.7 \pm 1.3$ \\
\hline \multicolumn{5}{|c|}{ Plasma SA (dpm/nmol) } \\
\hline$\%$ Direct & $21 \pm 4$ & $23 \pm 2$ & $27 \pm 3$ & $20 \pm 3$ \\
\hline$\left[{ }^{14} \mathrm{C}\right]$ UDP-glucose & $3.5 \pm 0.9$ & $3.4 \pm 0.8$ & $3.2 \pm 2.2$ & $2.2 \pm 1.2$ \\
\hline \multicolumn{5}{|c|}{ Liver SA (dpm/nmol) } \\
\hline$\left[{ }^{14} \mathrm{C}\right] \mathrm{PEP}$ & $3.6 \pm 1.2$ & $4.4 \pm 0.6$ & $3.6 \pm 1.8$ & $4.4 \pm 0.5$ \\
\hline \multicolumn{5}{|c|}{ Liver SA (dpm/nmol) } \\
\hline$\%$ Indirect & $46 \pm 4$ & $36 \pm 7$ & $39 \pm 6$ & $24 \pm 4^{\mathrm{A}}$ \\
\hline
\end{tabular}

Specific activities of radioactively labeled plasma glucose, hepatic UDP-glucose, and PEP were used to calculate the contribution of plasma glucose and PEP gluconeogenesis to the hepatic UDP-glucose pool following $\left[{ }^{3} \mathrm{H}-3\right]$ glucose and $\left[\mathrm{U}-{ }^{14} \mathrm{C}\right]$ lactate infusions in rats at the completion of pancreatic insulin clamp studies. \% direct is the percentage of the hepatic UDP-glucose pool derived from plasma glucose calculated as the ratio of the specific activities of liver [ $\left.{ }^{3} \mathrm{H}\right]$ UDP-glucose and plasma $\left[{ }^{3} \mathrm{H}-3\right]$ glucose. \% indirect is the percentage of the hepatic UDP-glucose pool derived from PEP gluconeogenesis, calculated as the ratio of the specific activities of $\left[{ }^{14} \mathrm{C}\right]$ UDP-glucose and $2 \times\left[{ }^{14} \mathrm{C}\right] \mathrm{PEP}$. ${ }^{A} P<0.01$ vs. vehicle. SA, specific activity. dpm, disintegrations per minute. 

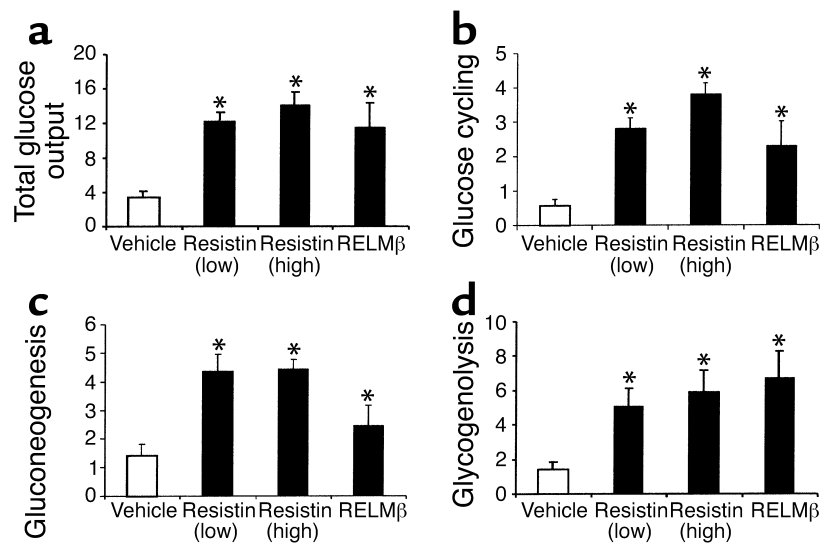

Figure 4

Effect of resistin and RELM $\beta$ on hepatic glucose fluxes $(\mathrm{mg} / \mathrm{kg} / \mathrm{min}$ ) during insulin clamp studies. (a) Effect of resistin and RELM $\beta$ on total glucose output (in vivo flux through glucose-6-phosphatase). (b) Effect of resistin and RELM $\beta$ on the rate of glucose cycling. (c) Effect of resistin and RELM $\beta$ on the rate of PEP gluconeogenesis. (d) Effect of resistin and RELM $\beta$ on the rate of glycogenolysis. ${ }^{*} P<0.05$ vs. vehicle.

the liver via phosphorylation of plasma glucose is also a substrate for dephosphorylation via glucose-6-phosphatase. This futile cycle between glucokinase and glucose-6-phosphatase is commonly named glucose cycling and accounts for the difference between the total glucose output (flux through glucose-6-phosphatase) and glucose production.

To further delineate the mechanisms responsible for the effect of recombinant resistin and RELM $\beta$ infusion on hepatic glucose production, we estimated the in vivo flux through glucose-6-phosphatase and the relative contributions of glucose cycling, gluconeogenesis, and glycogenolysis to glucose output (Table 2 and Figure 4). Figure 4 depicts the effect of resistin and RELM $\beta$ on the rates of hepatic glucose fluxes during the pancreatic insulin clamp procedure. In the presence of similar plasma insulin concentrations, the rate of glucose production (shown in Figure 3) was increased by resistin and by RELM $\beta$. Table 2 displays the $\left[{ }^{14} \mathrm{C}\right] \mathrm{PEP}$, $\left[{ }^{3} \mathrm{H}\right]$ UDP-glucose, $\left[{ }^{14} \mathrm{C}\right]$ UDP-glucose, and $\left[{ }^{3} \mathrm{H}-3\right]$ glucose specific activities used to calculate the contribution of PEP and plasma glucose (\% indirect and \% direct in Table 2) to the hepatic glucose-6-phosphate pool. Data obtained using the specific activity of UDP-galactose (not shown) confirmed the results obtained with UDP-glucose. These data allowed us to estimate the in vivo fluxes through glucose-6-phosphatase and the rates of glucose cycling, PEP gluconeogenesis, and glycogenolysis in all groups. As shown in Figure 4, the flux through glucose-6-phosphatase was markedly increased by resistin and RELM $\beta$ in parallel to the effect on glucose production. Consistent with this marked increase in overall glucose output, the rate of glucose cycling was also increased in resistin- and RELM $\beta$-infused rats compared with vehicle-infused animals. Thus short-term infusion of the adiposederived protein resistin and of the gut-derived protein
RELM $\beta$ lead to marked stimulation of in vivo glucose6-phosphatase flux. The latter increase was accounted for by marked increases in both gluconeogenesis and glycogen breakdown.

\section{Discussion}

Insulin resistance is strongly linked to central obesity $(18,19)$. In the short term, overfeeding rapidly leads to impaired hepatic and then peripheral insulin action in humans (20) and animals $(21,22)$. The molecular basis for this response remains elusive. Increased flux of FFAs rapidly induces hepatic and peripheral insulin resistance and thus may play a significant role in the development of this form of insulin resistance (23-25). However, it is also becoming increasingly evident that adipose tissue and the gut are not just sites of (respectively) energy storage and nutrient absorption, but are also active endocrine organs (1-10, 26-29). Among the numerous circulating proteins that are derived at least partly from either adipose cells or intestinal epithelial cells, some have potent effects on energy and intermediary metabolism and on insulin signaling (1-10, 26-29). Of interest, resistin is expressed at higher levels in intra-abdominal than subcutaneous fat depots in humans (30), and RELM $\beta$ is a secreted protein specifically expressed in epithelial intestinal cells. Finally, the insulin-sensitizing effects of PPAR- $\gamma$ agonists (13) may be partly due to the regulation of the biosynthesis and secretion of adipose-derived proteins, including resistin (1) and Acrp30/adiponectin $(7,9)$.

Our results provide an explanation for the recent finding that the intraperitoneal injection of epitopetagged recombinant resistin (resistin-F; total dose 32 $\mu \mathrm{g} /$ mouse) worsens glucose tolerance in mice (1). The latter effect was observed following two intraperitoneal injections of resistin-F, 14 hours and 2 hours prior to the glucose tolerance test (1). Of note, the metabolic effects of resistin reported herein were maximal during the low-dose resistin infusion, which was designed to increase circulating levels of resistin by two- to fivefold above endogenous mouse levels. No further impairment in hepatic insulin action was detected with increases in circulating resistin levels up to about 15 -fold higher than basal levels. The present study provides the first evidence that increases in circulating resistin or RELM $\beta$ levels markedly stimulate glucose production in the presence of fixed physiologic insulin levels. It should also be noted that the circulating levels of important counterregulatory hormones, such as glucagon and corticosterone, were similar in the four experimental groups.

To begin investigating the mechanisms by which resistin and RELM $\beta$ increase the net production of glucose by the liver, we next estimated the overall rate of glucose output (in vivo flux through glucose-6-phosphatase) and the relative contribution of hepatic glucose phosphorylation (glucose cycling), gluconeogenesis, and glycogenolysis to this flux. Our assessment of glucose-6-phosphatase flux revealed an increase of 
approximately threefold with resistin and RELM $\beta$ infusion compared with vehicle infusion. This increase closely paralleled that seen with net glucose production, suggesting that activation of glucose-6-phosphatase by resistin and RELM $\beta$ is a likely mode of action. Of interest, the marked upregulation all pathways involved in the formation of liver glucose-6-phosphate (gluconeogenesis, glycogenolysis, and glucose cycling) induced by resistin and RELM $\beta$ is also consistent with the increased flux through glucose-6-phosphatase being the driving force for the enhanced rate of glucose output.

The discovery of potent metabolic actions of resistin, which is exclusively expressed in differentiated adipose cells, further supports the notion of crosstalk between energy storage organs (adipose tissue) and dominant insulin target organs such as the liver $(7,8)$. Furthermore, the infusion of recombinant RELM $\beta$, which shares sequence homology with resistin $(2,3)$, also rapidly induced hepatic insulin resistance. In this regard, the secretion of RELM $\beta$ into the portal venous circulation may link the intestinal epithelium to the liver and promote changes in hepatic intermediate metabolism.

\section{Acknowledgments}

This work was supported by NIH Medical Scientist Training Grant T32 GM-07288 (to M.W. Rajala), NIH grants R01 DK-45024 and R01 DK-48321 to L. Rossetti and R01 DK-55758 to P.E. Scherer, a research grant from Pfizer (to P.E. Scherer), and by the Core Laboratories of the Albert Einstein College of Medicine Diabetes Research and Training Center (grant P60 DK-20541).

1. Steppan, C.M., et al. 2001. The hormone resistin links obesity to diabetes. Nature. 409:307-312.

2. Holcomb, I.N., et al. 2000. FIZZ1, a novel cysteine-rich secreted protein associated with pulmonary inflammation, defines a new gene family. EMBO J. 19:4046-4055

3. Steppan, C.M., et al. 2001. A family of tissue-specific resistin-like molecules. Proc. Natl. Acad. Sci. USA. 98:502-506.

4. Rajala, M.W., et al. Cell type-specific expression and coregulation of murine resistin and resistin-like molecule- $\alpha$ in adipose tissue. Mol. Endocrinol. 16:1920-1930.

5. Yamauchi, T., et al. 2001. The fat-derived hormone adiponectin reverses insulin resistance associated with both lipoatrophy and obesity. Nat. Med. 7:941-946

6. Fruebis, J., et al. 2001. Proteolytic cleavage product of 30-kDa adipocyte complement-related protein increases fatty acid oxidation in muscle and causes weight loss in mice. Proc. Natl. Acad. Sci. USA. 98:2005-2010.

7. Berg, A.H., Combs, T.P., Du, X., Brownlee, M., and Scherer, P.E. 2001. The adipocyte-secreted protein Acrp30 enhances hepatic insulin action. Nat. Med. 7:947-952.
8. Combs, T.P., Berg, A.H., Obici, S., Scherer, P.E., and Rossetti, L. 2001. Endogenous glucose production is inhibited by the adipose-derived protein Acrp30. J. Clin. Invest. 108:1875-1881. doi:10.1172/JCI200114120.

9. Shimomura, I., Hammer, R.E., Ikemoto, S., Brown, M.S., and Goldstein, J.L. 1999. Leptin reverses insulin resistance and diabetes mellitus in mice with congenital lipodystrophy. Nature. 401:73-76.

10. Uysal, K.T., Wiesbrock, S.M., Marino, M.W., and Hotamisligil, G.S. 1997. Protection from obesity-induced insulin resistance in mice lacking TNFalpha function. Nature. 389:610-614.

11. McGarry, J.D. 1992. What if Minkowski had been ageusic? An alternative angle on diabetes. Science. 258:766-770.

12. Kahn, B.B., and Flier, J.S. 2000. Obesity and insulin resistance. J. Clin. Invest. 106:473-481.

13. Olefsky, J.M., and Saltiel, A.R. 2000. PPAR gamma and the treatment of insulin resistance. Trends Endocrinol. Metab. 11:362-368.

14. Rossetti, L., Smith, D., Shulman, G.I., Papachristou, D., and DeFronzo, R.A. 1987. Correction of hyperglycemia with phlorizin normalizes tissue sensitivity to insulin in diabetic rats. J. Clin. Invest. 79:1510-1515.

15. Wang, J., Liu, R., Hawkins, M., Barzilai, N., and Rossetti, L. 1998. A nutrient sensing pathway regulates leptin gene expression in muscle and fat. Nature. 393:684-688.

16. Rossetti, L., and Giaccari, A. 1990. Relative contribution of glycogen synthesis and glycolysis to insulin-mediated glucose uptake. A doseresponse euglycemic clamp study in normal and diabetic rats. J. Clin. Invest. 85:1785-1792.

17. Rossetti, L., et al. 1993. Mechanism by which hyperglycemia inhibits hepatic glucose production in conscious rats. Implications for the pathophysiology of fasting hyperglycemia in diabetes. J. Clin. Invest. 92:1126-1134.

18. Bjorntorp, P. 1991. Metabolic implications of body fat distribution. Diabetes Care. 14:1132-1143.

19. Kissebah, A.H. 1991. Insulin resistance in visceral obesity. Int. J. Obes. 15:109-115.

20. Clore, J.N., Helm, S.T., and Blackard, W.G. 1995. Loss of hepatic autoregulation after carbohydrate overfeeding in normal man. J. Clin. Invest. 96:1967-1972.

21. Oakes, N.D., Cooney, G.J., Camilleri, S., Chisholm, D.J., and Kraegen, E.W. 1997. Mechanisms of liver and muscle insulin resistance induced by chronic high-fat feeding. Diabetes. 46:1768-1774.

22. Wang, J., Obici, S., Morgan, K., Barzilai, N., Feng, Z., and Rossetti, L. 2001. Overfeeding rapidly induces leptin and insulin resistance. Diabetes. 50:2786-2791.

23. Boden, G., Chen, X., Ruiz, J., White, J.V., Rossetti, L. 1994. Mechanisms of fatty acid-induced inhibition of glucose uptake. J. Clin. Invest. 93:2438-2446

24. Bergman, R.N., et al. 2001. Central role of the adipocyte in the metabolic syndrome. J. Investig. Med. 49:119-126.

25. Sindelar, D.K., et al. 1997. The role of fatty acids in mediating the effects of peripheral insulin on hepatic glucose production in the conscious dog. Diabetes. 46:187-196.

26. DeFronzo, R.A., Ferrannini, E., Wahren, J., and Felig, P. 1978. Lack of gastrointestinal mediator of insulin action in maturity-onset diabetes. Lancet. 2:1077-1079.

27. Miyawaki, K., et al. 1999. Glucose intolerance caused by a defect in the entero-insular axis: a study in gastric inhibitory polypeptide receptor knockout mice. Proc. Natl. Acad. Sci. USA. 96:14843-14847.

28. Murata, M., et al. 2002. Ghrelin modulates the downstream molecules of insulin signaling in hepatoma cells. J. Biol. Chem. 277:5667-5674.

29. Tschop, M., Smiley, D.L., and Heiman, M.L. 2000. Ghrelin induces adiposity in rodents. Nature. 407:908-913.

30. McTerman, P.G., et al. 2002. Increased resistin gene and protein expression in human abdominal adipose tissue. J. Clin. Endocrinol. Metab. 87:2407-2413. 